\title{
Gut microbiota: a source of novel tools to reduce the risk of human disease?
}

\author{
Maria Carmen Collado ${ }^{1,2}$, Samuli Rautava ${ }^{3}$, Erika Isolauri ${ }^{3}$ and Seppo Salminen ${ }^{2}$
}

Modern civilization is faced with a progressive increase in immune-mediated or inflammatory health problems such as allergic disease, autoimmune disorders, and obesity. An extended version of the hygiene hypothesis has been introduced to emphasize the intimate interrelationship among diet, the immune system, microbiome, and origins of human disease: the modern infant, particularly when delivered by cesarean section and without the recommended exclusive breastfeeding, may lack sufficient stimulation of the mucosal immune system to generate a tolerogenic immune milieu and instead be prone to develop chronic inflammatory conditions. These deviations may take the form of allergic or autoimmune disease, or predispose the child to higher weight gain and obesity. Moreover, evidence supports the role of first microbial contacts in promoting and maintaining a balanced immune response in early life and recent findings suggest that microbial contact begins prior to birth and is shaped by the maternal microbiota. Maternal microbiota may prove to be a safe and effective target for interventions decreasing the risk of allergic and noncommunicable diseases in future generations. These results support the hypothesis that targeting early interaction with microbes might offer an applicable strategy to prevent disease.

\section{PERINATAL MICROBIAL CONTACT}

The main microbial exposition of neonates is provided by the maternal microbiota. Yet, it is not clear how and how much the specific composition of the maternal microbiota may influence microbiota development and programming for later health. It is, however, well established that the process of microbial colonization of the infant's gut impacts metabolic and immunologic development $(1,2)$.

\section{Microbial Exposure In Utero}

The development of the human microbiome has long been assumed to start at birth and increase in diversity until acquiring an adult type-like composition around the first to the third year of life. However, microbial colonization of the human infant may begin earlier. The dogma of sterile intrauterine environment has recently been challenged by reports on detection of diverse microbes in placenta, umbilical cord, amniotic fluid, and meconium (3-10). Taking these preliminary observations together, the contact with the complex bacterial communities is clearly already initiated in utero and the impact of maternal microbiota may be more important than we had previously believed. In addition, these data suggest that an internal route may exist that enables the transport of bacteria from the mother to the fetus.

There are several sources and routes of microbial contact to the neonate and infant. Maternal microbial transmission is known to happen in the entire animal kingdom, including invertebrates and vertebrates (11). Experimental evidence in mice has been reported to support this notion $(12,13)$. Maternal bacteria present in blood would reach the placenta tissue, from which microbes could reach the amniotic fluid and be swallowed by the fetus $(3,4,8)$ or transfer into the fetal circulation, as has been demonstrated from maternal cells (14) and fetal transfer DNA material to maternal serum (15). The translocation of commensal bacteria from the mother to the fetus and neonate has been reported to have a variety of routes, for example, through the mesenteric lymph nodes, breast tissue, and skin. These preliminary observations suggest that contact with microbial populations of the extrauterine world is already initiated in utero. The type of contact is determined by the mother's intestinal microbiota, health, and body composition during pregnancy. Maternal health issues such as type 2 diabetes mellitus and history of atopic disease have been shown to impact meconium microbiota composition $(8,16)$. Furthermore, specific shifts in maternal gut microbial composition have been associated with maternal factors such as body mass index and weight gain during pregnancy $(17,18)$. In one of the first long-term follow-up studies, early differences in fecal microbiota composition could predict overweight in children in later life (19). Also, maternal obesity has an impact on infant microbiota development during the first month of life (20). In pregnant women with obesity, a vicious cycle of nonfavorable metabolic development may be generated if their altered gut microbiota composition is transferred to the infant $(20,21)$. We have shown that microbiota composition during pregnancy has an impact on fetal health programming,

\footnotetext{
The first two authors contributed equally to this work.

${ }^{1}$ Institute of Agrochemistry and Food Technology (IATA-CSIC), Spanish National Research Council, Valencia, Spain; ${ }^{2}$ Functional Foods Forum, University of Turku, Turku, Finland; ${ }^{3}$ Department of Pediatrics, University of Turku and Turku University Hospital, Turku, Finland. Correspondence: Maria Carmen Collado (mcolam@iata.csic.es) 


\section{Microbiota in early life $\quad$ Review}

presumably through altered serum biochemical variables of relevance to nutritional and health status $(17,18)$. In addition, maternal health including conditions such as allergy and obesity may affect milk microbiota, resulting in reduced levels of Bifidobacterium spp. compared to healthy mothers $(22,23)$.

\section{Breast Milk as the Link Between Mother and Infant}

Microbiota of the healthy, breastfed, vaginally delivered, fullterm infant who remains healthy for a longer follow-up time is considered the gold standard. After birth, transfer of the microbiota continues, and it is modified by breastfeeding and other dietary regimens. Breastfeeding represents the main postnatal link between mother and infant.

Beyond the nutritional composition, breast milk contains a number of bioactive components that are thought to be protective and to supplement innate immunity, impacting infant microbiota composition and health $(24,25)$. This protection is provided by components such as regulatory cytokines and growth factors, human milk oligosaccharides and milk microbiota that support and guide the immune system development and maturation. We have reported that maternal nutritional status affects the immunomodulatory potential of milk in terms of microbes and immunomodulatory factors (TGF$\beta 2$, sCD14, and cytokines) (21). Importantly, there are many uncharacterized components in human milk whose functions have been only partially elucidated.

Milk microbiota has also been described in rhesus monkey (26) and in other mammals such as the dairy cow (27) as well as in human breast milk samples (28-34). Our recent work using pyrosequencing demonstrated a large microbial biodiversity present in colostrum samples, with clear but mild temporal variations during the first 6 mo of breastfeeding (28). The initial microbial community was dominated by lactic acid bacteria such as Weisella, Leuconostoc, or Lactococcus. Milk microbiome composition is influenced by mode of delivery (28) but also, by maternal health during lactation $(31,32)$. Lower abundance of Bifidobacterium spp. has been reported in mothers with atopic disease compared to those observed in healthy mother (23).

The origin and biological role of milk bacteria has not yet been unveiled. Recently, the presence of microbes has been also reported in human breast tissue $(35,36)$ suggesting that specific microbes are inhabitant of breast and milk duct epithelium. This community was distinct from those found in skin, gut, vagina or mouth.

\section{EARLY GUT MICROBIOTA COMPOSITION AND HEALTH AND DISEASE}

Intensive research efforts attempting to elucidate early gut colonization patterns and factors which modulate perinatal microbiota acquisition have been motivated by experimental and epidemiological data which demonstrate a strong association between aberrant gut microbiota composition with a variety of inflammatory or immune-mediated diseases, including atopic disease, inflammatory bowel disease, type 1 diabetes mellitus, celiac disease, and obesity (37). It is of particular interest that changes in gut microbiota species and diversity observed in the first weeks or months of life appear to precede the development of atopic disease and atopic immune phenotype (37-40). We have also reported aberrant early gut microbiota composition in infants who later become overweight $(18,19)$. It must be noted, however, that it is questionable whether the microbiota alterations are really cause or consequence of a specific disease; however, it has been proven a direct relationship between alterations in microbiota composition and diversity and high risk to develop specific diseases as obesity and allergy as an example of the most common problem in infant population. These data suggest that perinatal gut colonization patterns have a potential role in the development of obesity and overweight. We hypothesize that early microbial contact influences immune programming which has direct consequences to health and disease. However, there is also epidemiological evidence on the role of lactic acid bacteria and probiotic bacteria in protecting infants from allergy (41). In the same manner, women who reported habitual probiotic dairy product use should have a reduced risk of spontaneous preterm delivery (42).

\section{DEVIATIONS IN PERINATAL MICROBIAL CONTACT, IMMUNE MATURATION, AND RISK OF DISEASE}

Early interaction with microbes and microbial colonization is often disturbed by factors such as cesarean section delivery and antibiotic therapy. Important lessons regarding microbial immune programming may be learned from epidemiological data on the impact of such perturbations.

\section{Mode of Delivery}

It is well established that infants born by cesarean section enter the extrauterine world ill-prepared compared to vaginally delivered neonates and are at increased risk for neonatal morbidities such as respiratory distress and hypoglycemia. These challenges are thought to result from lack of stress signals induced by labor in the fetus and the mother which is also reflected in immune markers measured from cord blood or in the neonatal period (43). Recently, more attention has been given to differences in early microbial contact related to the mode of birth. An accumulating body of evidence indicates that vaginally and surgically delivered neonates exhibit distinct gut colonization patterns $(6,7,33,44,45)$. The differences in gut microbiota composition may still be observed at the age of $7 \mathrm{y}$ (46). Bifidobacterium-dominated microbiota is more frequent in breastfed than among formula-fed infants. The transfer of specific Bifidobacterium strains from mothers to breastfed infants has been reported $(47,48)$, suggesting unique and specific maternal microbial transfer. In parallel, the mode of delivery has also been reported to affect immune development. More pronounced humoral immune responses have been detected in cesarean section-delivered infants as compared to vaginally delivered infants throughout the first year of life (49), whereas $\mathrm{T}$ helper 1-type immune responses are reportedly reduced in infants born by cesarean section during the first $2 \mathrm{y}$ of life (50). 


\section{Review | Colladoet al.}

Dissecting the individual contributions of labor-induced endogenous stress signals and microbial contact during delivery to normal immune development and health would entail rigorous analyses in which elective cesarean sections performed before the onset of labor and nonelective cesarean sections performed during labor are carefully separated from each other and compared to vaginal delivery. Unfortunately, not all studies distinguish between elective and nonelective cesarean sections. We have previously reported that elective but not nonelective cesarean section delivery is associated with aberrant microbial composition in breast milk (28) but whether the aberrant infant gut colonization patterns or immune development resulting from delivery mode is also confined to elective cesarean section deliveries is not as of present known.

Western countries worldwide are suffering a progressive increase of autoimmune and metabolic diseases, and the disemination is particularly conspicuous in infant populations. This increase may be related to a parallel enhancement in the rates of cesarean section deliveries, which have increased beyond the recommended level of $15 \%$, almost doubling in the last decade according to the World Health Organization. Cesarean section as a mode of delivery appears to increase the risk of a large array of noncommunicable diseases in later life. Indeed, an increased risk for atopic diseases, asthma, celiac disease and obesity among others was reported in children born by cesarean delivery (51-53). Several epidemiological studies have suggested that the risk of asthma is increased in children born by cesarean section. Not all studies report such association but a meta-analysis of 23 epidemiological studies concluded that the risk of asthma is $20 \%$ greater in children born by cesarean section as compared to those born vaginally but no analyses were performed to distinguish between elective and nonelective cesarean sections. A recent large cohort study of more than 37,000 Norwegian children concluded that children born by cesarean section have a modestly increased risk (relative risk $=1.17,95 \%$ confidence interval $=1.03-1.32$ ) of current asthma at the age of $36 \mathrm{mo}$ (54). The risk appeared similar in children born by elective and nonelective cesarean section. In contrast, the risk of celiac disease appears to be increased only in children born by elective but not by nonelective cesarian section according to a population-based case-control study of more than 65,000 children from Sweden (55). Meta-analyses of epidemiological studies also suggest that being born by cesarean section is strongly associated with increased body mass index, overweight and obesity in adulthood (56) as well as a $20 \%$ increase in the risk of type 1 diabetes mellitus (57).

\section{Early Antibiotic Exposure}

Antimicrobial therapy is known to cause significant but often transient perturbations in the indigenous intestinal microbiota. Individuals subjected to antibiotic therapy early in life therefore provide an opportunity to investigate the consequences of early disturbances in microbiota composition. Little is known about immune development in antibiotic-treated infants but there are ample data to suggest an association between early antibiotic exposure and risk of immune-mediated disease, which may imply that disturbing early host-microbe interaction has long-term immune and health consequences. In a nested casecontrol study of 36 patients with inflammatory bowel disease (IBD) and 360 healthy controls conducted in Canada, individuals with IBD were significantly more likely to have received antibiotics during the first year of life (58). Similar results with a clear dose-response pattern were obtained in an epidemiological study from Finland (59). In addition to IBD, antibiotic exposure in the first year of life has been observed to be associated with a small but significant increase in body mass (60).

It is important to recognize the inherent confounding effects resulting from the infection, suspected or proven, for which the antibiotics have been prescribed. It is also possible that any observed associations between antibiotic exposure and subsequent disease may be the result of recall bias or reverse causation. Even given these limitations, these still are compelling data to suggest that early life exposure to antibiotic agents is associated with increased risk of noncommunicable disease in later life. In a Swedish birth cohort study of more than 5,000 children, antibiotic exposure in the first week of life independently increased the risk of asthma at school age (relative risk $=2.3,95 \%$ confidence interval $=1.2-4.2$ ). Intriguingly, maternal antibiotic use during pregnancy has also been linked to increased prevalence of childhood asthma in the offspring (61), which may be interpreted to suggest that immune programming by microbes may begin during fetal life.

\section{Immune Programming and Early Microbial Contact}

The notion of fetal origins of human disease has become widely accepted within the context of metabolic and cardiovascular disorders. It has been suggested that prenatal programming may also be influenced by microbial contact (62). Consistently with this notion, changes in cord blood innate immune gene expression patterns have been observed in neonates whose mothers live in a farming environment and are thus presumably exposed to a wide variety of microbes (63). Such a prenatal environment has previously been reported to protect the offspring from the development of atopic disease (64).

In addition to this indirect fetal bacterial exposure, there are data to suggest that the fetus may be in direct contact with microbes in utero. The role of microbes as causative factors in premature rupture of membranes and preterm labor is well established. Whilst chorionamnionitis caused by bacteria such as Ureaplasma urealyticum is a recognized risk factor for neonatal morbidities including necrotizing enterocolitis, cerebral palsy and bronchopulmonary dysplasia, it is also becoming widely accepted that nonpathogenic bacteria are present in the placenta and amniotic fluid in healthy, term pregnancies (62). Bacterial DNA is consistently found in meconium suggesting fetal contact with microbes in amniotic fluid $(5,8,22)$. We have recently reported that microbial DNA belonging most commonly to Bifidobacterium spp. and Lactobacillus spp. was present in all 29 placentas obtained after sterile elective cesarean section at term (65). The hypothesis of prenatal microbial immune programming is corroborated by our results, according to which fetal gut innate immune gene expression patterns 


\section{Microbiota in early life $\quad$ Review}

are modulated by microbes in the placenta (65). In preterm infants, systemic neonatal inflammatory responses have been reported to be modulated in a species-specific fashion by microbes in the placenta (66).

These long-term health implications of aberrant early microbial contact resulting from factors such as cesarean section delivery or antibiotic exposure not only serve as empirical support for the notion of microbial immune programming in early life, but also suggest that modulation of early microbial contact might be an effective means to reduce the risk of disease in these high-risk infants. The emerging notion of prenatal microbial immune programming may be taken to suggest that such interventions might be effective during pregnancy.

\section{MATERNAL MICROBES AS HOST REGULATORS}

How the maternal microbiota impacts on offspring's microbial composition and development and how maternal microbes affect the immune system during early life constitutes a key issue that deserves further investigation. Furthermore, an intimate relationship among host genetics and bioactive components present in human milk should be linked to the infant microbiota colonization and immune system development. For all those facts, we emphasize the relevance of the key relationship between diet, the immune system, and microbiome and origins of human disease. The Western infant, particularly the cesarean section-delivered, antibiotic-exposed and devoid of the recommended breastfeeding, may lack sufficient stimulation of the mucosal immune system to create a tolerogenic immune milieu and increase the risk to develop chronic inflammatory conditions, which may also take the form of allergic or autoimmune disease, or predispose the child to obesity and/or other diseases. In recent years, microbiota studies have provided relevant advances towards the detection and identification of specific microbes and microbial consortia as well as their molecules contributing to the host metabolisms, physiology and also, health.

Moreover, the influence of maternal microbiota on neonatal microbiota composition and immune system development constitutes a key issue that deserves further investigation. The microbiota is the most relevant environmental source of microbial stimulation and may provide the first signal for the immune system development and maturation $(1,2)$. Maintenance of intestinal homeostasis requires a key relationship between microbiota and immune system. In mammals, homeostasis is maintained as the host Toll-like receptors (TLRs) recognize bacterial ligands. It has been reported that maternal transmission rather than defective innate immunity, influences the specific microbiota composition of TLR-deficient mice (67). Now it is demonstrated that food ingredients, toxins, synthetic substances and environmental pollutants influence epigenomic gene regulation as well as post-translational modifications and transcriptional activities (68). There are three distinct, but closely inter-acting, epigenetic mechanisms modulated by nutritional factors and microbes. These mechanism include histone modifications, methylation of DNA, and microRNAs (miRNAs). Together, they are able to regulate specific gene expression, not only fetal development but also throughout the entire life. On the other hand, miRNAs have been discovered as a novel additional level of control of TLR signaling (69). It is clear that microbiota is an indispensable partner in the immune response, but few studies have addressed the impact the microbiota has on miRNA expression. Recent findings suggest that microRNAs as well as secretory antibodies present, both in the intestine and in milk, are also key regulators of gut homeostasis and mucosal immunity (70-72) and modulate the neonatal immune system. Microbes and miRNAs are thus able to act as potential epigenomic modifiers regulating host gene expression.

\section{DIET AND MICROBES:TOOLS TO MODIFY EARLY MICROBIAL EXPOSITION}

Modulation of an unbalanced indigenous microbiota constitutes the rationale of probiotic therapy and opens new possibilities for the prevention and treatment of diseases in which microbial dysbiosis plays a relevant role. The contribution of specific gut bacteria, along with life-style, to the maintenance of microbial equilibrium is being investigated to improve our understanding of the etiological factors underlying specific disorders and to develop more efficient strategies for their management. Modification of the gut microbiota early in life has also attracted scientific interest, since the period during the first months of life when the establishment of the microbiota and immune system maturation are not yet completed affords an important opportunity for immune education. Thus, pregnancy and early infancy, to our knowledge, are the key critical periods and also, potential targets for dietary strategies and food-based interventions focusing on the reduction of risk disease. Gut microbiota modulation by use of probiotics strains and/or prebiotics early in life would envisage an important opportunity for health programming.

Interestingly, nutrition counseling and probiotic intervention have been shown to have a different effect on mothers suffering gestational diabetes (GD), whereby probiotics reduce the risk of the disorder while dietary counseling reduces the risk of fetal macrosomia and overgrowth as GD consequence (73). A recent meta-analysis showed a significant reduction in the prevalence and incidence of atopic eczema in children aged 2-7 y whose mothers received probiotics during pregnancy (74). In line with these observations, a recent finding has shown that perinatal probiotic intervention was able to moderate the excessive weight gain during childhood, the impact being higher at $4 \mathrm{y}$ of life (75). Furthermore, placenta and fetal immune physiology may be modulated by specific probiotic maternal dietary intervention (76) and also, probiotics consumption can modulate the composition of immune molecules such as transforming growth factor (TGF)- $\beta 2$ present in breast milk $(77,78)$. In addition, probiotic bacteria consumed by the lactating mother have been detected in breast milk and infant feces (79). The importance of these phenomena are also underscored by the results from a clinical trial which demonstrated that probiotics administered to the pregnant and brest-feeding mother significantly reduced the occurrence of atopic eczema 
in high-risk infants (80). However, even the potential effect of probiotics, there are still some points to be targeted as the identification of probiotic-strain, the dose, the time and duration of treatment. Further research is needed at this point and also, the effects of early intervention on long follow-up studies in infant population are still unknown.

Scarce but increasing data on prebiotic interventions in early life are available. The most common oligosaccharide compounds that have prebiotic effects used in infant population include galacto-oligosaccharides (GOS), fructo-oligosaccharides (FOS) and their combination. Clinical data have shown the effect of those prebiotics in early life could lead to the prevention of specific diseases in infants as allergic problems (including atopic dermatitis and allergic asthma) and food allergy (81). A recent report compiling data from five randomized controlled trials (infants from 0 to 24 mo of age) revealed significant decrease in the infectious episodes and also, in the rate of overall infections in the prebiotic group as compared with the placebo group (82). The prebiotic effects are promising although the number of studies is still scarce to have a general picture of short- and long-term effects on microbiota modulation and then, impacting on health.

On the other hand, in recent years, there has been a remarkable increase in the use of a unique microbial replacement therapy, "fecal microbiota transplantation" which has been shown to be effective when treating Clostridium difficile infections, colitis and irritable bowel syndrome $(83,84)$. Then, identification, isolation, and characterization of new bioactive elements, including microbes (probiotics) or their growth factors (prebiotics), would be interesting in order to personalize their use to improve and/or maintain health in those cases needed during pre- and/or postnatal period.

\section{CONCLUSIONS}

Improved understanding of the role of early microbial contact in immune and metabolic development provide the rationale for new therapeutic approaches to modify microbial exposure during the critical time periods of fetal development and early infancy. The emerging notion of host-microbe interaction in utero bridges two contemporary lines of research attempting to elucidate the pathogenesis of common noninfectious diseases. The novel conceptual frame of reference combines the "hygiene hypothesis" $(85,86)$ with the "Barker hypothesis" (87) and suggests that both dietary and microbial environments during fetal life and early infancy modify immune and metabolic programming and have far-reaching consequences for later health and the risk of immune-mediated and inflammatory disease. Within this context, the detrimental long-term health impact of disturbances in early microbial contact as a result of antibiotic exposure or cesarean section delivery need to be taken into account when such interventions are considered. Perhaps more importantly, dietary interventions such as probiotics aiming to modify bacterial exposure during pregnancy and infancy have to be viewed with great promise to divert the rising prevalence of autoimmune and allergic disease as well as obesity and metabolic disorders.
Clinical probiotic research should be based on well-defined targets known to be causally related to development of disease as well as preclinical data on the effects of the rigorously specified probiotic strains used. In addition to mechanistic basic research, prospective randomized controlled trials are the gold standard for establishing true causal relationships between the observed effects. Given the natural history of autoimmune and metabolic disease, long-term follow-up is essential to confirm the efficacy of the interventions.

\section{STATEMENT OF FINANCIAL SUPPORT}

No financial assistance was received to support this study.

Disclosure: No conflicts of interest.

\section{REFERENCES}

1. Hooper LV, Littman DR, Macpherson AJ. Interactions between the microbiota and the immune system. Science 2012;336:1268-73.

2. Hooper LV, Macpherson AJ. Immune adaptations that maintain homeostasis with the intestinal microbiota. Nat Rev Immunol 2010;10:159-69.

3. Jiménez E, Marín ML, Martín R, et al. Is meconium from healthy newborns actually sterile? Res Microbiol 2008;159:187-93.

4. Jiménez E, Fernández L, Marín ML, et al. Isolation of commensal bacteria from umbilical cord blood of healthy neonates born by cesarean section. Curr Microbiol 2005;51:270-4.

5. Moles L, Gómez M, Heilig H, et al. Bacterial diversity in meconium of preterm neonates and evolution of their fecal microbiota during the first month of life. PLoS ONE 2013;8:e66986.

6. Dominguez-Bello MG, Costello EK, Contreras M, et al. Delivery mode shapes the acquisition and structure of the initial microbiota across multiple body habitats in newborns. Proc Natl Acad Sci USA 2010;107:11971-5.

7. Song SJ, Dominguez-Bello MG, Knight R. How delivery mode and feeding can shape the bacterial community in the infant gut. CMAJ 2013;185:373-4.

8. Gosalbes MJ, Llop S, Vallès Y, Moya A, Ballester F, Francino MP. Meconium microbiota types dominated by lactic acid or enteric bacteria are differentially associated with maternal eczema and respiratory problems in infants. Clin Exp Allergy 2013;43:198-211.

9. Vallès Y, Gosalbes MJ, de Vries LE, Abellán JJ, Francino MP. Metagenomics and development of the gut microbiota in infants. Clin Microbiol Infect 2012;18:Suppl 4:21-6.

10. Aagaard K, Ma J, Antony KM, Ganu R, Petrosino J, Versalovic J. The placenta harbors a unique microbiome. Sci Transl Med 2014;6:237.

11. Funkhouser LJ, Bordenstein SR. Mom knows best: the universality of maternal microbial transmission. PLoS Biol 2013;11:e1001631.

12. Perez PF, Doré J, Leclerc M, et al. Bacterial imprinting of the neonatal immune system: lessons from maternal cells? Pediatrics 2007; 119:e724-32.

13. Donnet-Hughes A, Perez PF, Doré J, et al. Potential role of the intestinal microbiota of the mother in neonatal immune education. Proc Nutr Soc 2010;69:407-15.

14. Lo ES, Lo YM, Hjelm NM, Thilaganathan B. Transfer of nucleated maternal cells into fetal circulation during the second trimester of pregnancy. Br J Haematol 1998;100:605-6.

15. Lo YM, Tein MS, Lau TK, et al. Quantitative analysis of fetal DNA in maternal plasma and serum: implications for noninvasive prenatal diagnosis. Am J Hum Genet 1998;62:768-75.

16. Hu J, Nomura Y, Bashir A, et al. Diversified microbiota of meconium is affected by maternal diabetes status. PLoS ONE 2013;8:e78257.

17. Collado MC, Isolauri E, Laitinen K, Salminen S. Distinct composition of gut microbiota during pregnancy in overweight and normal-weight women. Am J Clin Nutr 2008;88:894-9.

18. Santacruz A, Collado MC, García-Valdés L, et al. Gut microbiota composition is associated with body weight, weight gain and biochemical parameters in pregnant women. Br J Nutr 2010;104:83-92. 


\section{Microbiota in early life $\mid$ Review}

19. Kalliomäki M, Collado MC, Salminen S, Isolauri E. Early differences in fecal microbiota composition in children may predict overweight. Am J Clin Nutr 2008;87:534-8.

20. Collado MC, Isolauri E, Laitinen K, Salminen S. Effect of mother's weight on infant's microbiota acquisition, composition, and activity during early infancy: a prospective follow-up study initiated in early pregnancy. Am J Clin Nutr 2010;92:1023-30.

21. Laitinen K, Collado MC, Isolauri E. Early nutritional environment: focus on health effects of microbiota and probiotics. Benef Microbes 2010;1:383-90.

22. Collado MC, Laitinen K, Salminen S, Isolauri E. Maternal weight and excessive weight gain during pregnancy modify the immunomodulatory potential of breast milk. Pediatr Res 2012;72:77-85.

23. Grönlund MM, Gueimonde M, Laitinen K, et al. Maternal breast-milk and intestinal bifidobacteria guide the compositional development of the Bifidobacterium microbiota in infants at risk of allergic disease. Clin Exp Allergy 2007;37:1764-72.

24. Petherick A. Development: Mother's milk: A rich opportunity. Nature 2010;468:S5-7.

25. Walker A. Breast milk as the gold standard for protective nutrients. J Pediatr 2010;156(2 Suppl):S3-7.

26. O’Sullivan A, He X, McNiven EM, Haggarty NW, Lönnerdal B, Slupsky CM. Early diet impacts infant rhesus gut microbiome, immunity, and metabolism. J Proteome Res 2013;12:2833-45.

27. Quigley L, O'Sullivan O, Stanton C, et al. The complex microbiota of raw milk. FEMS Microbiol Rev 2013;37:664-98.

28. Cabrera-Rubio R, Collado MC, Laitinen K, Salminen S, Isolauri E, Mira A. The human milk microbiome changes over lactation and is shaped by maternal weight and mode of delivery. Am J Clin Nutr 2012; 96:544-51.

29. Jeurink PV, van Bergenhenegouwen J, Jiménez E, et al. Human milk: a source of more life than we imagine. Benef Microbes 2013;4:17-30.

30. Delgado S, Collado MC, Fernández L, Rodríguez JM. Bacterial analysis of breast milk: a tool to differentiate Raynaud's phenomenon from infectious mastitis during lactation. Curr Microbiol 2009;59:59-64.

31. Hunt KM, Foster JA, Forney LJ, et al. Characterization of the diversity and temporal stability of bacterial communities in human milk. PLoS ONE 2011;6:e21313.

32. Collado MC, Delgado S, Maldonado A, Rodríguez JM. Assessment of the bacterial diversity of breast milk of healthy women by quantitative realtime PCR. Lett Appl Microbiol 2009;48:523-8.

33. Jost T, Lacroix C, Braegger C, Chassard C. Stability of the maternal gut microbiota during late pregnancy and early lactation. Curr Microbiol 2014;68:419-27.

34. Jost T, Lacroix C, Braegger CP, Rochat F, Chassard C. Vertical mother-neonate transfer of maternal gut bacteria via breastfeeding. Environ Microbiol 2014;16:2891-904.

35. Urbaniak C, Cummins J, Brackstone $\mathrm{M}$, et al. Microbiota of human breast tissue. Appl Environ Microbiol 2014;80:3007-14.

36. Xuan C, Shamonki JM, Chung A, et al. Microbial dysbiosis is associated with human breast cancer. PLoS ONE 2014;9:e83744.

37. Isolauri E, Kalliomäki M, Rautava S, Salminen S, Laitinen K. Obesity Extending the hygiene hypothesis. In: Brandtzaeg P, Isolauri E, Prescott S, eds. Microbial Host-Interaction: Tolerance versus Allergy. Nestle Nutrition Institute Workshop Ser Pediatr Program, Nestle Ltd. Basel, Switzerland: Vevey/S.Karger AG, 2009:75-89.

38. Kalliomäki M, Kirjavainen P, Eerola E, Kero P, Salminen S, Isolauri E. Distinct patterns of neonatal gut microflora in infants in whom atopy was and was not developing. J Allergy Clin Immunol 2001;107:129-34.

39. Björkstén B, Sepp E, Julge K, Voor T, Mikelsaar M. Allergy development and the intestinal microflora during the first year of life. J Allergy Clin Immunol 2001;108:516-20.

40. Abrahamsson TR, Jakobsson HE, Andersson AF, Björkstén B, Engstrand L, Jenmalm MC. Low diversity of the gut microbiota in infants with atopic eczema. J Allergy Clin Immunol 2012;129:434-40, 440.e1-2.

41. Bertelsen RJ, Brantsæter AL, Magnus MC, et al. Probiotic milk consumption in pregnancy and infancy and subsequent childhood allergic diseases. J Allergy Clin Immunol 2014;133:165-71.e1-8.
42. Myhre R, Brantsæeter AL, Myking S, et al. Intake of probiotic food and risk of spontaneous preterm delivery. Am J Clin Nutr 2011;93:151-7.

43. Cho CE, Norman M. Cesarean section and development of the immune system in the offspring. Am J Obstet Gynecol 2013;208:249-54.

44. Roger LC, Costabile A, Holland DT, Hoyles L, McCartney AL. Examination of faecal Bifidobacterium populations in breast- and formula-fed infants during the first 18 months of life. Microbiology (Reading, Engl) 2010;156(Pt 11):3329-41.

45. Jost T, Lacroix C, Braegger C, Chassard C. Assessment of bacterial diversity in breast milk using culture-dependent and culture-independent approaches. Br J Nutr 2013;110:1253-62.

46. Salminen S, Gibson GR, McCartney AL, Isolauri E. Influence of mode of delivery on gut microbiota composition in seven year old children. Gut 2004;53:1388-9.

47. Makino H, Kushiro A, Ishikawa E, et al. Mother-to-infant transmission of intestinal bifidobacterial strains has an impact on the early development of vaginally delivered infant's microbiota. PLoS ONE 2013;8:e78331.

48. Makino H, Kushiro A, Ishikawa E, et al. Transmission of intestinal Bifidobacterium longum subsp. longum strains from mother to infant, determined by multilocus sequencing typing and amplified fragment length polymorphism. Appl Environ Microbiol 2011;77:6788-93.

49. Huurre A, Kalliomäki M, Rautava S, Rinne M, Salminen S, Isolauri E. Mode of delivery - effects on gut microbiota and humoral immunity. Neonatology 2008;93:236-40.

50. Jakobsson HE, Abrahamsson TR, Jenmalm MC, et al. Decreased gut microbiota diversity, delayed Bacteroidetes colonisation and reduced Th1 responses in infants delivered by caesarean section. Gut 2014;63:559-66.

51. Thavagnanam S, Fleming J, Bromley A, Shields MD, Cardwell CR. A meta-analysis of the association between Caesarean section and childhood asthma. Clin Exp Allergy 2008;38:629-33.

52. Decker E, Engelmann G, Findeisen A, et al. Cesarean delivery is associated with celiac disease but not inflammatory bowel disease in children. Pediatrics 2010;125:e1433-40.

53. Barros FC, Matijasevich A, Hallal PC, et al. Cesarean section and risk of obesity in childhood, adolescence, and early adulthood: evidence from 3 Brazilian birth cohorts. Am J Clin Nutr 2012;95:465-70.

54. Magnus MC, Håberg SE, Stigum $\mathrm{H}$, et al. Delivery by Cesarean section and early childhood respiratory symptoms and disorders: the Norwegian mother and child cohort study. Am J Epidemiol 2011;174:1275-85.

55. Mårild K, Stephansson O, Montgomery S, Murray JA, Ludvigsson JF. Pregnancy outcome and risk of celiac disease in offspring: a nationwide casecontrol study. Gastroenterology 2012;142:39-45.e3.

56. Darmasseelane K, Hyde MJ, Santhakumaran S, Gale C, Modi N. Mode of delivery and offspring body mass index, overweight and obesity in adult life: a systematic review and meta-analysis. PLoS ONE 2014;9:e87896.

57. Cardwell CR, Stene LC, Joner G, et al. Caesarean section is associated with an increased risk of childhood-onset type 1 diabetes mellitus: a metaanalysis of observational studies. Diabetologia 2008;51:726-35.

58. Shaw SY, Blanchard JF, Bernstein CN. Association between the use of antibiotics in the first year of life and pediatric inflammatory bowel disease. Am J Gastroenterol 2010;105:2687-92.

59. Virta L, Auvinen A, Helenius H, Huovinen P, Kolho KL. Association of repeated exposure to antibiotics with the development of pediatric Crohn's disease-a nationwide, register-based finnish case-control study. Am J Epidemiol 2012;175:775-84.

60. Murphy R, Stewart AW, Braithwaite I, Beasley R, Hancox RJ, Mitchell EA ISAAC Phase Three Study Group. Antibiotic treatment during infancy and increased body mass index in boys: an international cross-sectional study. Int J Obes (Lond) 2014;38:1115-9.

61. Stensballe LG, Simonsen J, Jensen SM, Bønnelykke K, Bisgaard H. Use of antibiotics during pregnancy increases the risk of asthma in early childhood. J Pediatr 2013;162:832-838.e3.

62. Rautava S, Luoto R, Salminen S, Isolauri E. Microbial contact during pregnancy, intestinal colonization and human disease. Nat Rev Gastroenterol Hepatol 2012;9:565-76.

63. Loss G, Bitter S, Wohlgensinger J, et al.; PASTURE study group. Prenatal and early-life exposures alter expression of innate immunity genes: the PASTURE cohort study. J Allergy Clin Immunol 2012;130:523-30.e9. 
64. Roduit C, Wohlgensinger J, Frei R, et al.; PASTURE Study Group. Prenatal animal contact and gene expression of innate immunity receptors at birth are associated with atopic dermatitis. J Allergy Clin Immunol 2011;127:179-85, 185.e1.

65. Rautava S, Collado MC, Salminen S, Isolauri E. Probiotics modulate hostmicrobe interaction in the placenta and fetal gut: a randomized, doubleblind, placebo-controlled trial. Neonatology 2012;102:178-84.

66. Fichorova $\mathrm{RN}$, Onderdonk $\mathrm{AB}$, Yamamoto $\mathrm{H}$, et al.; Extremely Low Gestation Age Newborns (ELGAN) Study Investigators. Materna microbe-specific modulation of inflammatory response in extremely lowgestational-age newborns. MBio 2011;2:e00280-10.

67. Ubeda C, Lipuma L, Gobourne A, et al. Familial transmission rather than defective innate immunity shapes the distinct intestinal microbiota of TLR-deficient mice. J Exp Med 2012;209:1445-56.

68. Kussmann M, Van Bladeren PJ. The Extended Nutrigenomics - Understanding the Interplay between the Genomes of Food, Gut Microbes, and Human Host. Front Genet 2011;2:21.

69. O'Neill LA, Sheedy FJ, McCoy CE. MicroRNAs: the fine-tuners of Toll-like receptor signalling. Nat Rev Immunol 2011;11:163-75.

70. Kosaka N, Izumi H, Sekine K, Ochiya T. microRNA as a new immuneregulatory agent in breast milk. Silence 2010;1:7.

71. Rogier EW, Frantz AL, Bruno ME, et al. Secretory antibodies in breast milk promote long-term intestinal homeostasis by regulating the gut microbiota and host gene expression. Proc Natl Acad Sci USA 2014;111:3074-9.

72. Quinn SR, O'Neill LA. A trio of microRNAs that control Toll-like receptor signalling. Int Immunol 2011;23:421-5.

73. Luoto R, Laitinen K, Nermes M, Isolauri E. Impact of maternal probioticsupplemented dietary counselling on pregnancy outcome and prenatal and postnatal growth: a double-blind, placebo-controlled study. Br J Nutr 2010;103:1792-9.

74. Doege K, Grajecki D, Zyriax BC, Detinkina E, Zu Eulenburg C, Buhling KJ. Impact of maternal supplementation with probiotics during pregnancy on atopic eczema in childhood-a meta-analysis. Br J Nutr 2012;107:1-6.

75. Luoto R, Kalliomäki M, Laitinen K, Isolauri E. The impact of perinatal probiotic intervention on the development of overweight and obesity: followup study from birth to 10 years. Int J Obes (Lond) 2010;34:1531-7.
76. Rautava S, Lu L, Nanthakumar NN, Dubert-Ferrandon A, Walker WA TGF- 32 induces maturation of immature human intestinal epithelial cells and inhibits inflammatory cytokine responses induced via the NF-?B pathway. J Pediatr Gastroenterol Nutr 2012;54:630-8.

77. Rautava S, Kalliomäki M, Isolauri E. Probiotics during pregnancy and breast-feeding might confer immunomodulatory protection against atopic disease in the infant. J Allergy Clin Immunol 2002;109:119-21.

78. Böttcher MF, Abrahamsson TR, Fredriksson M, Jakobsson T, Björkstén B. Low breast milk TGF-beta2 is induced by Lactobacillus reuteri supplementation and associates with reduced risk of sensitization during infancy. Pediatr Allergy Immunol 2008;19:497-504.

79. Abrahamsson TR, Sinkiewicz G, Jakobsson T, Fredrikson M, Björkstén B. Probiotic lactobacilli in breast milk and infant stool in relation to oral intake during the first year of life. J Pediatr Gastroenterol Nutr 2009;49:349-54.

80. Rautava S, Kainonen E, Salminen S, Isolauri E. Maternal probiotic supplementation during pregnancy and breast-feeding reduces the risk of eczema in the infant. J Allergy Clin Immunol 2012;130:1355-60.

81. Lohner S, Küllenberg D, Antes G, Decsi T, Meerpohl JJ. Prebiotics in healthy infants and children for prevention of acute infectious diseases: a systematic review and meta-analysis. Nutr Rev 2014;72:523-31.

82. Oozeer R, van Limpt K, Ludwig T, et al. Intestinal microbiology in early life: specific prebiotics can have similar functionalities as human-milk oligosaccharides. Am J Clin Nutr 2013;98:561S-71S.

83. Di Bella S, Drapeau C, García-Almodóvar E, Petrosillo N. Fecal microbiota transplantation: the state of the art. Infect Dis Rep 2013;5:e13.

84. Austin M, Mellow M, Tierney WM. Fecal microbiota transplantation in the treatment of Clostridium difficile infections. Am J Med 2014; 127:479-83.

85. Strachan DP. Hay fever, hygiene, and household size. BMJ 1989; 299:1259-60.

86. Rautava S, Ruuskanen O, Ouwehand A, Salminen S, Isolauri E. The hygiene hypothesis of atopic disease-an extended version. J Pediatr Gastroenterol Nutr 2004;38:378-88.

87. Barker DJ. The developmental origins of adult disease. Eur J Epidemiol 2003;18:733-6. 